\title{
The Importance of Realism, Character, and Genre: How Theatre Can Support the Creation of Likeable Sociable Robots
}

\author{
Louise LePage ${ }^{1}$ (D) \\ Accepted: 22 February 2020 / Published online: 12 December 2020 \\ (c) The Author(s) 2020
}

\begin{abstract}
Stage plays, theories of theatre, narrative studies, and robotics research can serve to identify, explore, and interrogate theatrical elements that support the effective performance of sociable humanoid robots. Theatre, including its parts of performance, aesthetics, character, and genre, can also reveal features of human-robot interaction key to creating humanoid robots that are likeable rather than uncanny. In particular, this can be achieved by relating Mori's (1970/2012) concept of total appearance to realism. Realism is broader and more subtle in its workings than is generally recognised in its operationalization in studies that focus solely on appearance. For example, it is complicated by genre. A realistic character cast in a detective drama will convey different qualities and expectations than the same character in a dystopian drama or romantic comedy. The implications of realism and genre carry over into real life. As stage performances and robotics studies reveal, likeability depends on creating aesthetically coherent representations of character, where all the parts coalesce to produce a socially identifiable figure demonstrating predictable behaviour.
\end{abstract}

Keywords Sociable robots · Uncanny valley $\cdot$ Character $\cdot$ Theatre $\cdot$ Realism $\cdot$ Genre

\section{The Likeability of the Bunraku Puppet and the Importance of Its 'total appearance'}

Mori's hypothesis of the uncanny valley, illustrated by his graph [see Mori, 1970/2012], posits a scale of affinity. On the $\mathrm{y}$-axis, this scale of affinity posits not only positive results; it also descends into the negative realm of the uncanny. The $\mathrm{x}$-axis represents a scale of degrees-of-realism of human likeness. Mori's graph, in short, indicates that the two are causally related. The more realistically humanlike an artificial object appears, the more affinity it will engender in human observers until the tipping point when responses plunge into the uncanny valley before rising again to the figure of the healthy human, which attracts the highest degree of affinity. Mori reflects upon reasons for the likability of the bunraku puppet (Fig. 1) and, in the process, indicates that realism may be a more subtle and broad category than is

Louise LePage

louise.lepage@york.ac.uk

1 Department of Theatre, Film, Television and Interactive Media, University of York, Baird Lane, Heslington, York YO10 5GB, UK suggested by degrees-of-realism of appearance. Mori positions the bunraku puppet as inspiring more affinity on his graph than any other inanimate object, second only to an ill and a healthy person. His reflection reads as follows:

I don't think that, on close inspection, a bunraku puppet appears similar to a human being. Its realism in terms of size, skin texture, and so on, does not even reach that of a realistic prosthetic hand. But when we enjoy a puppet show in the theater, we are seated at a certain distance from the stage. The puppet's absolute size is ignored, and its total appearance, including hand and eye movements, is close to that of a human being. So, given our tendency as an audience to become absorbed in this form of art, we might feel a high level of affinity for the puppet. [14]

Mori observes that the degree of realism of the physical appearance of the bunraku puppet is not high but that, in spite of this, we feel a high level of affinity for it. $\mathrm{He}$ indicates that the puppet's total appearance as a humanlike object is important and incorporates a number of elements, including physical appearance and size as well as hand and eye movements. In Mori's account, the realism of some of these elements offsets or compensates for others that are 


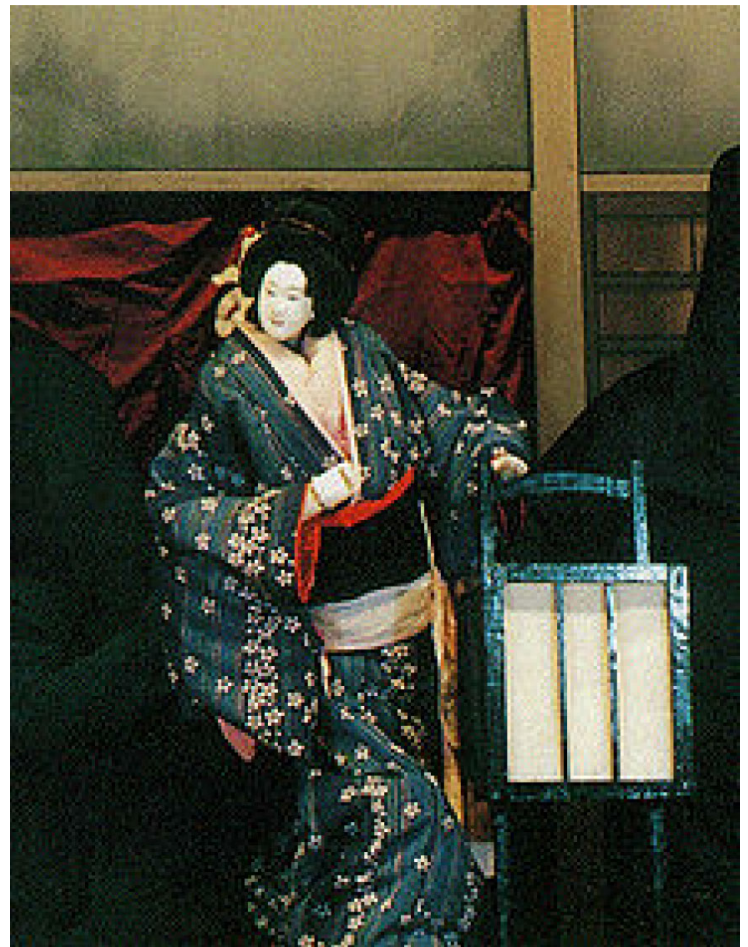

Fig. 1 The character Osono, from the play Hade Sugata Onna Maiginu (艶容女舞衣), in a performance by the Tonda Puppet Troupe of Nagahama, Shiga Prefecture

less-than-realistic. Mori also indicates that the puppet's total appearance is bound to its theatrical context in which an audience sits at some distance from the stage and has a 'tendency [...] to become absorbed in this form of art' [14].

It may be that the bunraku puppet belongs more properly on the first peak of Mori's graph, rather than the second, and that the first peak should be higher than the second. However, as a theatre scholar interested in the design and applications of sociable robots, Mori's reflections about how realism connects to total appearance, where total appearance includes elements of physical appearance while extending beyond it, are evocative. Indeed, it is worthwhile to examine more closely the relationship between realism not only to the physical components of an object but also to elements bound up in its context, which frames and directs the way an object is interpreted. In the case of the bunraku puppet, the context is the stage, where matters of aesthetics - specifically, character and genre-are important. However, stories and characters are fundamental to real life contexts, too, so have relevance beyond the stage. Yuval Noah Harari, in Sapiens: A Brief History of Humankind, tells how the 'imagined order' [9] has worked through history to establish communities-social, cultural, political, economic, religious, and so on. Through myths, the imagined order-an inter-subjective phenomenon-embeds itself materially and shapes our desires.
This paper will examine theatrical parts, processes, and performances with a view to identifying theatrical insights with social implications. Its key questions are: What is indicated by Mori's reference to total appearance and how can it be useful to robotics researchers? How does Mori's notion of 'total appearance' connect to realism in creating likeable sociable robots? And what can enhanced knowledge and understanding of theatre-including performance, aesthetics, character, and genre-contribute to research that seeks to create humanlike objects that are likeable as opposed to uncanny?

Robotics, psychology, narrative studies, and theatre can assist answering these questions, as can analysis of performing robots cast in stage plays in sociable roles. At times, this paper's analysis and corresponding arguments arise from first-person responses to robots and performing robots. This discussion may sometimes be unsubstantiated by empirical evidence, in the form of, for example, survey results. Such reflections are intended as propositions contributing to ongoing discussions about how to create likeable sociable robots rather than as hard and fast evidence.

\section{Making a case for theatre in the work of social robotics}

Theatre can assist in understanding the causes of audience responses to robots where these extend beyond biology and evolutionary psychology. Robots were given form by a dramatic play called R.U.R.[4] about a century ago. There are no essential species-specific qualities, processes, or biologically evolved mechanisms that cause humans to like humanlike, but not too humanlike, artificial objects because Homo sapiens did not evolve in an environment populated by android Homo sapiens. Androids evolved, initially, in the imagination, in stories. Studies of the uncanny valley sensibly borrow from areas beyond robotics and animation to theorise that uncanny responses to artificial humanlike objects are likely bound to fear of death, disease, threat, and the unknown (including the supernatural). Such work is important but theatre offers additional explanations to account for audience responses, which are manipulated by stage representations and actions designed to make spectators jump in fright, experience eeriness, or develop strong affinity for a character. Given that the very notion of robots derives from the imagination and a stage play, it is worth considering the role that performance and narrative structures play in our human-robot social engagements by reframing the human-robot relation as a culturally informed one.

A number of scholars recognize the possibilities and benefits of exploring robotics through theatre and performance, in theory and in practice. Some have focused on ways in which acting theories and approaches can support robotics program- 
ming (including Lu and Smart [14]; Breazeal [2]; Hoffman [12, 13]; Knight [14]; and Knight and Gray [14]) while others have explored how elements of performance-including language, facial expressions, the body, posture, and movement—can be employed expressively in the design and programming of robots (Ishiguro [14]; Lin [14]; Lu and Smart [14]; Breazeal [2]; Bretan et al. [3]; Knight [14]; Knight and Gray [14]; Knight and Simmons [14]; Jochum and Murphey [14]; Popat [14]; LePage [14, 14]).

$\mathrm{Lu}$ and Smart offer a rationale for the relation between robotics and theatre when they observe that 'both theatre and HRI aim to replicate some elements of humanity' and that 'HRI and theatre are both inherently interactive' [14]. Theatre, they suggest, may be used 'both as the mode for modeling interactions' - such as with the use of motion capture technology for modelling ways in which human beings move- 'and as the venue for testing the interactions' [14]. In the first place, modelling the interactions of actors is useful because actors are highly effective physical performers. Further, as Heather Knight observes, some performance methodologies, such as those of physical theatre, have 'a long history of encoding and honing expression' and, as such, provide 'pre-processed methodologies for interpreting and communicating human non-verbal behaviors' [14]. In the second place, the performing arts provide roboticists, as Tzung-De Lin observes, with access to the public. For roboticists working on robots aimed to be used in everyday life, particularly in social settings and interactions, the public, in the form of audiences, 'may be seen as an invaluable resource to be mobilized [...] to test people's responses to robots' [14] with a view to making robots with which people will want to interact.

Theatre also offers a complex multi-person/robot social landscape in which to explore the role and design of robots. Lin suggests that the robot lab is 'an impoverished imitation of the human "social" world', that it "emphasizes cues, such as gazes and gestures, and certain relationships, such as a caregiver-infant relationship' [14]. Lin prefers the stage context, explaining that,

Theater, $[\ldots]$ although still limited, provides a much richer model of social interactions through its scenarios and settings. In theatre, robot actors can be embedded in many-to-many social relationships, which not only move beyond the one-to-one relationship typical of human-robot interaction but also are closer to the interactions we experience in everyday life. [14]

This is an important point for those working towards the design of humanoid robots intended for compelling social interactions with people. In the real world, sociable participants are required to fulfil more than one social role at a time. Theatre, while continuing to offer a controlled context, provides a site to test robot characters performing a variety of social roles, e.g. a sister, a daughter, a carer, a friend, and so on, in a variety of social settings.

Lin also argues that theatre can offer an effective medium for fostering acceptance of robots as sociable characters. Jochum, Vlachos, Christoffersen, Nielsen, Hameed, and Tan [14] propose, more explicitly, 'that the co-creation of theatre between dramatists and robot researchers can assist the acceptance of social robots by addressing user concerns in specific application scenarios'. Theatre offers lively 'what if?' scenarios that allow robotics engineers and theatremakers, imaginatively, to identify and respond to potential human-robot social situations and relationships, as well as designs and implications for sociable characters and roles.

The sorts of speculative contexts for sociable robots that have been effectively staged to date include a care scenario between a human and a socially assistive robot (Jochum et al. [14]); worker robots in the home that reject their programming and refuse to work (Hirata and Ishiguro, I, Worker [11]); a bank-worker robot that, one day, decides it would be nice to buy pizza for everyone (Mick Livermore [14]); a robot companion for a dying woman that recites poetry (Hirata and Ishiguro, Sayonara [14]); a robot stand-in for a depressed recluse that fulfils a variety of social roles, including sister, servant, and friend (Hirata and Ishiguro [42]); a performer stand-in for a writer who dislikes the task of delivering public lectures (Rimini Protokoll and Thomas Melle, Uncanny Valley [38]); domestic-worker robots and a romantic-companion robot for a single, lonely man (Denisart [6]); a robot avatar stand-in for a man who wants to live his life more perfectly than he, himself, is capable (Talenti [14]); and a robot companion for a woman with Alzheimers that also performs as the woman's (dead) husband (Pipeline Theatre Company, Spillikin: A Love Story) [34].

Theatre obviously does not enjoy the cultural reach of films or the novel. However, theatre's liveness-its temporal and physical proximity to audiences - gives it the capacity.

Theatrical structures and processes can assist in the creation and direction of believable, humanlike robots, which, lacking high-level intelligence and personality or character themselves, can nonetheless be made to appear as if they possess such qualities. Indeed, some theatre-makers have produced startling results by drawing artfully upon theatrical methods to create character. The performance of Geminoid F as android Ikumi in Three Sisters: Android Version is a case in point [14]. (This performance will be analysed in some depth in the next section.)

Before closing this section, a few words of caution about employing theatre in robotics research. Stage characters are coherent and meaningful in a way that people in real life rarely are. In Western drama, a character generally acts according to coherent objectives, which are meaningful in the broader terms of the narrative and its themes. In contrast, as Lin observes, '(a)ctual social situations are much noisier' and 
'the information communicated by actions is less clear' [14]. Theatre, then, offers a relatively complex laboratory context, which encourages emotional and critical engagement with stage actor-characters, but it remains a laboratory that simplifies much messier real-world contexts. In certain respects, of course, this may be an advantage for robotics researchers seeking to explore specific elements in a controlled setting.

Also, stage robots, unlike autonomous social robots designed for real-world scenarios, are not sociable characters or participants; they are aesthetic objects representing sociable characters or participants. This is important because audiences read aesthetic objects differently to objects they encounter in real life. On stage, nothing is really happening; the dramatic stakes for characters are not real. There is no tangible, impending risk to characters or audience members, and audiences are perfectly aware of this. Given this, and given the semantic connection of fear with uncanny responses, it may be that robots cast in stage scenarios reduce the potential for uncanny audience reactions.

A connected point of caution is that aesthetic objects and their actions are always overdetermined. They are loaded with meaning in a way that ordinary objects in everyday life are not. If a cup is dropped in your kitchen, you will probably think nothing of it other than that the person who dropped it was momentarily clumsy or careless. On stage, however, unless you are led to believe otherwise, you read the dropping of the cup as an intentional and meaningful action. A character who drops a cup may be interpreted as being nervous or inherently clumsy or showing signs of an onset of an illness.

It might be argued, of course, that robots are themselves overdetermined entities, even in real life, and that they will remain so until they have become sufficiently ubiquitous that they become mundane. Robots are always 'meaningful' [14]. We see this if we consider the 'resting' robot. Lu and Smart observe that a robot is 'often programmed to have "idle animations" which serve no explicit purpose, other than to communicate to others that it is active and ready, not dead' [14]. Robots, unlike humans or animals, are always signifying, even when they are doing nothing. They are not alive and have yet to become ordinary so while this is the case, theatre remains a compelling 'what if?' setting for the exploration of their design, character, and setting.

\section{The Status of Mind}

Robots are inherently performative; their identities derive entirely from their performances. They have no essential self to express. Lu and Smart are correct when they observe that, '(u)ltimately, all social interactions can be viewed as acting roles which the robot must perform', indicating that both actors and robots have 'to get as close as possible to the unobtainable ideal (normal social player/actual character) by giving the correct outputs' [14]. However, for the robot, unlike for humans, the 'correct outputs' of character are entirely artful and performative, rather than expressive. Given this, the performative design, programming, and contextualisation of sociable robots are crucial to their effective reception.

The robot, akin to the Chinese room in Searle's thought experiment, does not have a mind that understands, nor does it need one, in order to be perceived as an apparently intelligent and self-determining agent. However, if the sociable robot is to be likeable, it needs more than to perform correct outputs; it needs to appear to be a sociable character, and this means seeming to have a mind.

The status of mind is important. Though K. Gray and D. M. Wegner's conclusion may be correct - that the appearance of an experiencing mind in machines is tied to uncanniness [8] — mind per se seems unlikely to be the problem. Indeed, the appearance of mind seems likely to be key in creating sociable robots. What matters is the type of character and mind indicated: just as strong affinity is bound to a meeting of like minds, uncanniness is bound to unpredictable or malevolent characters and minds, rather than mind per se.

\section{Science Fiction and the Imagination: How We Perceive Robots}

Human beings are adept at investing objects with personality. We have all seen children play with inanimate toys, bringing them, imaginatively, to life. Birnbaum et al. [1] (citing Friedman, Kahn, \& Hagman [2003] and Lee, Peng, Jin, \& Yan [2006]) refer to how '(p)eople tend to perceive robots as social actors and attribute to them humanlike traits, including mental states and personality'. My own playful explorations with a Nao robot interacting with groups of people [14] supports as much.

Before it says or does anything, audiences invest the humanoid robot with the promise, if not the fact, of intelligent autonomy, character, and life. The robot derives this promise in several ways. Firstly, the robot is an inherently science-fictional entity. The very word, 'robot', was coined by Karel Čapek's science-fiction play, R.U.R. (1920/21) [4] to describe humanlike artificial entities, produced in factories, serving humankind as slaves. In the play, these mechanical slaves turn, en masse, against their human oppressors, exterminating them. A couple of the robots, however, take on roles at the end of the play that are akin to those of Adam and Eve in the Garden of Eden, offering the promise of new life in paradise founded on innocence, love, and selflessness. This kind of narrative and set of character roles for robots have repeated themselves in our science fiction stories ever since, in the West if not the East. 
Many real-life robots significantly draw their potential identity from common cultural science-fictional depictions. Kriz, Ferro, Damera, and Porter III [14] provide evidence that cultural attitudes to robots are bound to science-fictional representations. Exploring 'the relationship between capabilities of robots portrayed in popular science fiction films and students' expectations about a real robot', the authors find that, with a few notable exceptions, expectations map fairly accurately onto their content analysis of science fiction films featuring robots.

Secondly, the humanoid robot is invested in the promise of autonomy, character, and life by virtue of its relation to the puppet. However, whereas the puppet has strings that compose a fundamental element of the puppet's lively appearance and form, the robot's 'strings' are hidden and we are invited to read the object as autonomous and, in its way, alive and self-determining, even when it is not.

All this has the effect of positioning spectators in cognitive readiness to identify humanoid robots as capable of intentional self-determination and as certain kinds of characters fulfilling certain kinds of roles, including roles that are threatening. From such a starting point, theatrical parts and processes serve to support the imaginative steps of spectators 'believing' a humanoid robot is a character, has a mind, ${ }^{1}$ and perceives them back in friendly or unfriendly terms. The humanoid robot need only perform its part well enough for the observer to infer mental states where none exist.

\section{An Account of How Audience Reception Theory Explains the Perception of a Robot's 'total appearance'}

Understanding how an audience gains an impression of a stage actor's total appearance, be this actor human, puppet, or robot, can assist the creation of a robot's total appearance. Elizabeth Ann Jochum and Todd Murphey, writing about uncanny responses to humanlike movement in robots [14], draw upon theatre scholar Bert O. States' influential theory of binocular vision [14]. They explain how, in the minds of the audience, the material reality of the stage is brought together with the imaginative realm, comprising mental concepts, which meaningfully identify the physical objects. So, for example, actor is brought together with character, and the real world of the theatre with the fictional world of the play.

\footnotetext{
${ }^{1}$ Chemers identifies the Eliza effect as being important to game designers. It is also important to humanoid robot designers. Chemers observes how 'humans are quite prone to perceive computer intelligences as possessing far greater depth, complexity, and emotional content than they possibly could' [5]. He also observes that the kind of cognitive dissonance bound to the Eliza effect is the sort 'that theatre artists from all ages have sought to foster; it, or something like it, is what Coleridge called "suspension of disbelief.".
}

Theatre exploits this process for dramatic effect. When audiences watch realistic drama, they watch performances that directors and actors work meticulously to invest with clues, juxtapositions, and gaps, which encourage audiences to perceive particular kinds of characters who have the potential for particular kinds of behaviours. Audiences join the dots of any given performance to construct a picture of a character. They bring their subjective perspectives and their culturally and socially shared knowledge to bear upon their perception of the character, and they assess its potential for action. Is it friend or is it foe? Should we like it or should we fear it? What will it do?

Roboticists know that 'the mechanisms underlying perception of individuals in our environment are predictive in nature (Urgen et al. [14]). They know that appearance is bound up with expectations about a given humanlike object and that if one's predictions about that object are violated, there is the potential for the uncanny to arise. Writing about the relation between appearance and movement, Urgen et al. explain:

(T)he form (appearance) of the visually presented agent provide(s) a context from which the subject infer(s) how the agent would move over time (e.g. a mechanical/robotic appearance would activate the semantic network that includes motion information associated with robotic appearances), the same way a preceding word group provides a context for the upcoming word in a sentence (e.g. I take coffee with cream and ("sugar" instead of "dog")), and activates the relevant semantic network associated with the word group.

However, what roboticists sometimes miss is the significance of the humanlike object's identity and corresponding character, which are implied by all the details of its appearance.

\section{How Affinity, Likeability, and Familiarity Are All Important for the Production of Shinwakan}

The character implied by the physical appearance and performance of a humanlike artificial object is fundamentally important if it is to inspire shinwakan, a neologism of Mori's creation that has come, most often, to be translated into the English word, 'affinity', although 'familiarity' and 'likeability' are also used. In fact, each of these English terms - affinity, likeability, and familiarity - has a role in producing shinwakan. We need to be familiar with the character type that composes and frames our perception of an artificial humanlike object in order to like or feel affinity with it. When Mori identifies the bunraku puppet as a particularly likeable artificial object, he assumes familiarity with 
it, some knowledge or experience of it. If we have never before encountered bunraku puppetry, we are unlikely to rate the puppet particularly highly on Mori's axis of affinity. We do not need to have seen a particular object before in order to like it-it can be a stranger to us (here I contradict the argument of Yamada, Kawabe and Ihaya [14]; and Kawabe, Sasaki, Ihaya, and Yamada [14])—but we do need to be able to categorise it, to identify it as a character type drawn from our stock of socially and culturally shared stories, be these historical, supernatural, political, expressionistic, comic, melodramatic, romantic, mythic, fairytale, horror, religious, surreal, socially realistic, or whatever. These stories are not merely the stories we read in books or see in films or on the stage, they are the stories that build our conception of the world (to refer back to Harari's Sapiens). To be strongly likeable, the character of the artificial object needs to appear to be familiar, like us, our potential kin or 'soul mate' (MacDorman qtd. in Wang et al. [14]). Something about it needs to cause us to feel we are 'in synchrony' with it, that we are experiencing a 'meeting of minds'. In short, if we are to experience strongly positive responses to an object, irrespective of its species form, we need to be able to identify it as a friend, not a foe, and predict its corresponding behaviours.

\section{Three Sisters: Android Version: An Example of a Very Likeable Stage Robot Character}

Character is a powerful element, exploited by theatre-makers casting robot performers in plays. The performances of robots cast as humanlike characters in plays can compensate for flaws in the physical performance of human likeness. Indeed, the form of a humanlike artificial object's character can operate so powerfully that it overrides the empirical features of its appearance and causes it to become extremely likeable.

The playwright and director, Oriza Hirata, creates 'android theatre' with Japan's Seinendan Theater Company, in collaboration with Osaka University Robot Theater Project, led by Hiroshi Ishiguro. Hirata has notoriously expounded opinions directly relevant to this paper, including: 'Actors do not need to have minds' and 'Actors need only act like robots' (Sasaki qtd. in Lin [14]). Hirata positions android performers alongside human ones in naturalistic stage plays with the intention of investing his robot performers with the illusion of mind and character. Avoiding the traditional methods of the naturalistic actor-character work operating at the level of psychology where the actor develops his character's backstory, relationships, and objectives, with a view to transforming himself into his character-Hirata attends, instead, to the physical details of both his android and human actors' performances, to make them as close to life as possible. This approach is based on Hirata's view that '(m)ost human communication is not empathic but rather based on learned patterns of response to stimuli' (qtd. in Poulton [14]).

While this may well be true, it is not sufficient as an account of how audiences respond to robot performers. Hirata's employment of hyper-realistic theatrical form works to direct audience attention and expectations in conventional ways, just as bunraku puppetry works conventionally in Mori's example. In theatrical realism and naturalism, the audience, the audience expects to engage with the details of surface performance in order to infer, and focus on, character psychology and, more particularly, the subtext underpinning the staged social interactions, irrespective of the form of the performer. Meticulously choreographing and modulating the physical performances of his human and android actors by attending to volume of speech, length of pauses, vocal intonation, speed of vocal delivery, quality and type of movement, details of facial expressions, and so on, Hirata exploits the audience's tendency to conflate real and imagined elements in their perception of a stage object's total appearance. He also exploits the structures of realist and naturalist drama, which operate from the assumption that underneath the surface appearances of human interactions lie psychological character truths. He co-opts these structures to fabricate the sensation of character, consciousness, and agency in his automata without these elements being evident in the robot performers themselves.

Geminoid F (the figure on the left in Fig. 2) is a teleoperated mechanical puppet that masquerades as humanlike autonomous android characters in Hirata's plays. How effective are Geminoid F's performances and what are the parts that make them effective? Ishiguro, Geminoid F's engineer, holds the view that facial expressions are key to Geminoid F's successful performance of its sophisticated android character, where success is judged by the robot's capacity to make audiences believe in, and weep for, it. Ishiguro argues that while humanlike appearance is important, it is so only insofar as it facilitates the expression of humanlike emotion: '(o)f course the robot needs to have a kind of a minimal (humanlike) appearance'; it would be no good for a robot to be, for example, '... just a cup or a kettle' because this would make it 'difficult to read the human-like emotions' [14].

This seems somewhat disingenuous given the exactitude of human likeness that Ishiguro has evidently aimed for in Geminoid F's look. It is true that the robot's highly humanlike face enables audiences to mistake its signs of emotions-its smiles and frowns-as the emotions themselves. Such emotional potential is important for its indication of an individual consciousness, which, in turn, is almost certainly required if empathetic responses are to be prompted in audiences. (We appear to have a tendency to feel for creatures, which themselves appear to feel.) However, Ishiguro has designed Geminoid F with a particular look, indicative of a socially significant identity, which signals far more than 


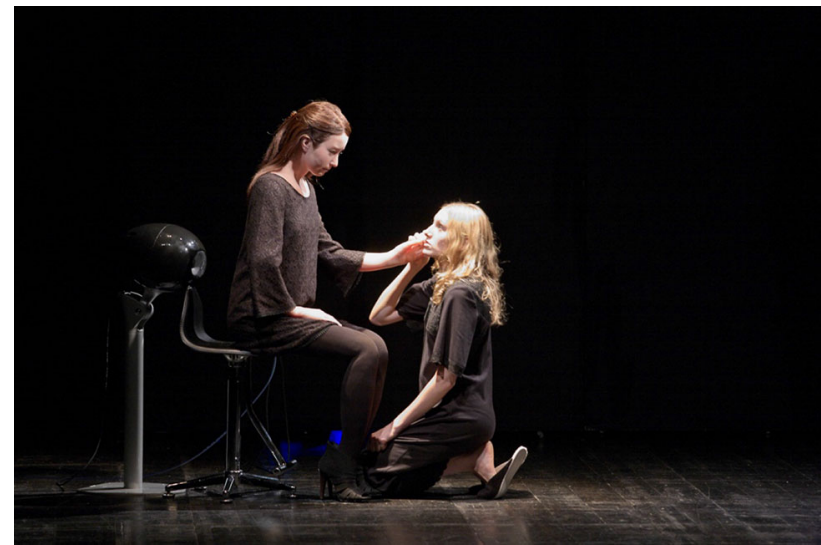

Fig. 2 Geminoid F (left) and Bryerly Long in Oriza Hirata's Sayonara. Photo (Tatsuo Nambu/Aichi Triennale 2010

mere consciousness. This identity operates to direct audience responses to the robot as a certain kind of character.

The costly avatar-type android character is performed by the robot performer, Geminoid F: a mechanical puppet. Its dialogue is pre-recorded and its movements are those of an actor backstage who operates the robot using a motion tracking system. To what degree is such a mechanical puppet successful at performing its sociable robot-avatar part? On the one hand, it is not successful in that, unlike a human actor, Geminoid F cannot transform itself physically, mentally, or emotionally into its character. Furthermore, its performance of a conscious and self-determining android character is flawed, with delays in verbal and gestural cues and, overall, there is a woodenness to the robot's performance. It is insufficiently quick and fluid at responding to the actions of those around it. However, in spite of such flaws, from the perspective of the audience and at the level of its imagination, Geminoid $\mathrm{F}$ transforms into android Ikumi. In a review of earlier work by Seinendan Theater Company, also featuring Geminoid $\mathrm{F}$ alongside other robot performers (Robovie R3s), Alexis Soloski remarks: 'these automata excite [...] sympathy to an equivalent, or perhaps even greater, degree than their human counterparts' [14], such that we are prompted to misperceive kinship and feel empathy for them. ${ }^{2}$ Meanwhile, having appeared in a film version of Sayonara (directed by Koji Fukada), Geminoid F was nominated for the best actress

\footnotetext{
2 Additional evidence of audience empathy for Hirata's stage robots is provided in the form of survey results responding to another of Hirata's android performances, I, Worker, which features Mitsubishi's Wakamaru robot. The two Wakamaru robots in this play are not as humanlike as the Geminoid F in Three Sisters, nor are their characters conceived as being as sociable or sophisticated as the character performed by the Geminoid F. However, Lin reports that their treatment by Hirata as sociable worker robots elicited empathetic responses from audience members. Quoting Kuroki (2010), Lin writes that a survey responding to a performance of $I$, Worker on 25 November 2008 revealed that ' 70 percent of the audience reported either feeling or moderately feeling empathy for the robots' [14].
}

award at the Tokyo International Film Festival in 2015. Even if the android did not ultimately win, the nomination indicates an effective performance of its character. Birnbaum et al. observe that people are generally willing to play along with the illusion that the robot is a sentient creature appropriate for relational interactions' [1]. Citing Sherry Turkle (2007), they report that people 'are often willing to ignore the mechanical aspects of the robot and to treat it in a manner similar to how they would respond to a fellow human being' [1].

In Hirata's Three Sisters, the characters of android and human Ikumi are foregrounded in their juxtaposition. Cast in comparative terms - indeed, on one occasion, the two figures are literally positioned side by side on stage - the collocation of android and human both exposes and disguises the distinctiveness of their species forms. In the process, audiences are invited to examine and compare the forms of the human and android figures in light of their responses to these forms. In the process, Hirata's stage play interrogates the role that species form plays in positioning audience responses in terms of positive or negative shinwakan.

In the first place, Hirata's presentation of human and android Ikumi side by side is notable for indicating that uncanniness may not necessarily connect exclusively or, even, primarily to artificial humanlike entities. Lin observes that,

When Ikumi first appears suddenly with an expressionless face onstage, a feeling of uncanniness - toward the human Ikumi, not the geminoid IKUMI-arises. The similarity of movements and sound of the two turns the idea of the uncanny valley upside down. [14]

The uncanniness arises from the abruptness and strangeness of human Ikumi's appearance alongside her android doppelgänger. The story has taught us, up to this point, that human Ikumi is dead so when she appears, we don't know how to place her and we don't know how to place her. The two Ikumis are almost indistinguishable in appearance terms. As Lin observes, their faces are similarly expressionless but, more than this, they are of a similar physical size, they wear their hair the same way, are dressed the same, and are likewise more or less motionless on stage (although human Ikumi walks whereas the android character drives herself in her wheelchair). Lin reports that, '(a)ccording to an anthropologist who attended as a member of the audience [of Three Sisters]', the feeling of eeriness arises in response to the puzzle: 'who is the real daughter'? (Lin quoting Feng [14]). When human Ikumi first appears and the two figures appear onstage together, looking so similar, we are, for a moment, doubtful about how to categorise them and during that moment, human Ikumi paradoxically appears to be one thing and another: familiar and abruptly 
foreign. Is human Ikumi real or is she another android or something else?

Another important feature of the performances of android and human Ikumi are the ways in which their species forms and roles are foregrounded in the performance, and the implications of these for their likeability. They are both quiet and thoughtful, with a tendency to be abrupt, which sometimes topples over into rudeness. However, android Ikumi repeatedly reminds us that, unlike her human original, she has no knowledge of death; she can smell but she cannot eat; she cannot lie; and she cannot forget. This may be significant in terms of her likeability, given Schwind et al.'s findings that 'the positive impression of a realistic animal is lost if it represents something other than itself' [14]. Geminoid F's performance also marks out her species differences by virtue of her mechanical acting, which, compared to her human counterpart's performance, lacks fluency and spontaneity. Also, seen up close, one can detect the vacancy behind the robot's eyes. Despite an apparent expression of emotion in the form of a gentle smile, there is no spark of life or mind behind the smile to lend it urgency or purpose. The smile is no more than a signifier. One would expect such species differences-some of which reveal themselves, in terms of acting, as flaws-to manifest negative audience responses towards the android. However, the opposite is true: faced with the android-human juxtaposition, it is android Ikumi who materializes as the more likeable character. According to Mori's theory, this should not be possible: one should not be able to feel greater empathy for an android than a human, particularly one whose performance of human likeness is flawed, occasionally jarringly so. So how does Hirata manage to direct an audience to such a positive, even empathetic, response for an android?

The answer lies with quality of character and the geminoid's performance of a sociable role. She appears sociable, warm, and responsive: she sits with her family and guests and partakes in conversations with them, seeming to demonstrate a high level of understanding of human needs and feelings; her voice is soft in tone and predictable in its modulations; and her turns of the head and range of expressions, including smiles, are sensitively choreographed by Hirata to indicate the android's conscious and thoughtful attention to the human characters in the scene. Such performative elements, combined with details of her appearance, mean that this physically attractive, woman-like, twenty-something android, demonstrating a sophisticated AI, conjures a quality of character that is intelligent, attractive, gentle, direct, calm, honest, compassionate, and, crucially, sociable. Indeed, of the two, it is human, not android Ikumi, who demonstrates qualities that might be deemed machine-like: human Ikumi seems comparatively cold, is frequently dissatisfied, less eager to please, and her voice has a harder, flatter quality to it. Human Ikumi's uncanniness may also connect to these qualities. Gray and Wegner observe that humans 'incapable of fear or love' are unnerving and that 'the uncanny valley may apply to... robotic humans' as well as humanlike robots [8].

Human Ikumi is the biological sister in the Fukazawa family but she does not perform the role in the sorts of ways we expect of, or culturally value in, a sibling. It is android Ikumi whose performance of a sister finds a more imaginatively and emotionally compelling form: she takes an interest in her elder sisters and brother and participates in the activities and concerns of the household with apparent selflessness and compassion. Android Ikumi is positioned in performative terms as kin to the Fukazawa siblings and in the process, she prompts the sisters (and her audiences) to experience positive shinwakan for her, a sense of synchronicity, a sense that she, despite her form as android, is friendly towards them, that she understands and likes them in a way that the real Ikumi appears not to. The fact that android Ikumi is not really Ikumi appears to matter less to these sisters (and, by implication, the audience) than her performance of the role of sister, which materialises in an idealized and friendly form.

In this example, we see a demonstration of the significance of dramatic character. The imaginary (character) and the real (performer) are fused into a singly perceived, dialectical phenomenon.

Some interesting questions arise from the representation of android Ikumi in Hirata's Three Sisters that engage with questions about the design and programming of sociable robots. How far might sociability be important to producing positive, as opposed to negative, shinwakan? (Negative shinwakan, here, does not necessarily refer to uncanniness but more generally to a lack of synchrony or kinship.) How far might predictability be important in positioning a performer as kin and eliciting positive shinwakan, or its converse, bukimi, i.e. eeriness (in the event that predictability corresponds with perceived threat)? Can an unsociable character, human or android, inspire positive feelings of kinship in audiences? Might my own cool feelings towards human Ikumi derive from her machinelike character qualities? Or might my response derive from the perceived contradictions in her form and performance and in her character role and character actions?

This section has identified performative elements that work to position Geminoid $\mathrm{F}$, cast in her role as android Ikumi, as a likeable figure. The importance of coherence of character, understood in aesthetic terms, will be picked up and explored in the next section. 


\section{Aesthetics, Genre, and Character Coherence}

\subsection{Aesthetics: A Better Term Than Attractiveness}

A study by Schwind, Leicht, Jäger, Wolf, and Henze asks the question: 'Is there an uncanny valley of virtual animals?' [14] Focusing on animated representations of cats in a variety of computer games, the study does something important: it substitutes attractiveness for aesthetics, explaining the substitution by way of its focus on animal-like objects rather than human-like ones.

Aesthetics is much richer terrain than attractiveness, which is subsumed by the broader category of the former. Aesthetics is the study of subjective and sensori-emotional values relating to art and beauty. As a branch of philosophy, it asks questions about the judgement of sentiment and taste and investigates how and why we find some things beautiful and not others. Aesthetics engages with ways in which artists imagine, create, and perform works of art as well as indicating styles and principles for a given genre of art (for example, distinguishing between the Impressionist versus Cubist aesthetic). In their study, Schwind et al. are interested in subjective and sensori-emotional values attaching to the representations of the cats as well as the coherency of the cats' representational categories, styles, and principles as they find form in their various animations.

\subsection{How the Significance of Realism Expands Beyond Degrees-Of-Realism}

In a point that engages with aesthetics, Schwind et al. identify problems with ' $(t)$ he manipulation of realism' in uncanny valley studies. The concept of realism, Schwind et al. note, can be compromised because it is "partially biased by other associations' [14]. This is an important observation because it starts to recognise the nuanced implications of realism, which extend beyond degrees-of-realism.

Realism indicates a representational form in artistic fields, including theatre, that connects to a distinct set of logics and styles. For example, realism offers a positivist representation of the world that follows the laws of cause and effect. You don't get demons, ghosts, monsters, or talking scarecrows in realistic theatre. (Such entities belong in, for example, surrealism, which operates at the level of the dream and, as such, refuses the logic of everyday life, adopting a more abstract and poetic style of representation.) Realism is distinctive from other forms - such as expressionism or surrealism - by virtue of its objectivity, its focus on appearance (on what is said, how things look and sound, how people relate to each other), as well as its implicit assumptions about people. In realism, people are understood to be fundamentally psychological individuals who are intelligent and capable of reasoned behaviours as they set about pursuing their goals by applying a variety of tactics and actions within recognisable social contexts. ${ }^{3}$ This conception of realism is, broadly, analogous with its meaning in uncanny valley studies, which, focusing on human likeness, targets appearance, and assumes a way of human being that is social, intelligent, and selfdetermining.

However, realism is complicated by the fact that it is categorised and structured by genre. Examples of genres include social realism, Epic Theatre, kitchen-sink drama, comedies (farce, satire, parody), tragedy, tragi-comedies, science fiction, dystopian dramas, detective dramas, romantic dramas, melodrama, verbatim drama, and so on. This is significant because the specific forms of stories in which realistic characters are cast function to clarify their roles, i.e. what those characters do and how they relate to society, at the same time as they influence audience expectations about those characters.

Consider the character of a male police officer. This character may be performed realistically by a single actor in a number of different dramatic genres and each time, the audience will engage with him differently, sometimes liking him, sometimes fearing him, sometimes rooting for him, and so on. In a comedy, the police officer figure is commonly depicted as a figure of fun or ridicule whereas, cast in a detective drama, he may feature as the hero of the drama, acting to protect the innocent. In a dystopian drama, the police officer may be one of the villains whereas in a television soap, he may be the object of our curiosity and sympathy as we watch him struggle to juggle work and home demands.

If a director were casting a single actor for the figure of a police officer in a farce, she may require him to grow a moustache, appear bald, use make-up to redden his nose, and ask him to smile inappropriately at everything - anything to contribute to the sense that this figure is to be ridiculed. If this same actor were to be cast as a police officer in a dystopian drama, he may be given slicked back hair, eyebrows that rise at the edges, and be required to wear a serious and sombre demeanour, facially and physically, at all times.

The key point, here, is that when we engage with a realistic figure, we look for clues to know how to interpret and categorise that figure according to genre. If we see a face sporting a serious expression, with eyebrows that are raised at the outer edges, we are likely to draw upon common cultural narratives categorising that character as, say, a villain.

\footnotetext{
${ }^{3}$ Surrealism, by contrast, might foreground the body and poetic images and allow for a logic of actions that is irrational and, possibly, supernatural.
} 


\subsection{How Character Impacts Upon Studies Investigating Degrees-Of-Realism in Relation to the Likeability of Artificial Humanlike Objects}

This notion of aesthetic character coherence is revealing when held up against studies presenting a face on a continuum of realism to test how people respond to human versus animated or cartoon abstractions. A number of such studies have produced results that contradict Mori's, or refined versions of Mori's theory. Some of these contradictions arise not because the theories are wrong but because insufficient attention has been paid to the characteristics of the figures represented or to their forms of representation, where such information indicates particular character types and sets up corresponding audience expectations, which connect to likeability and uncanniness.

Yamada et al.'s study [14] seeks to demonstrate the validity of their hypothesis that 'the uncanny valley phenomenon is determined not by the visual similarity to a real human, but the categorization difficulty for an object'. Their results are ambiguous with participant responses showing that 'the images that were difficult to categorize were not always negatively evaluated'. For example, the highest likeability score for Experiment 3 went to the most ambiguous facial categorisation (see the middle face of the bottom line of faces in Fig. 3). Meanwhile, results attaching to Experiments 1 and 2 show that the highest likeability scores were attributed to the stuffed human (see the figure on the far right of the top line of faces in Fig. 3) and the cartoon dog (see the figure on the far left of the second line of faces in Fig. 3). The authors propose that attractiveness may be a factor in these results. This is possible. However, other reasons for these likeability scores are character type and character coherence.

The real human male face in Experiment 1 (see the top line of images in Fig. 3) is placed at one end of a scale of human likeness and a 'stuffed human' appears at the other end. What is key, here, is that the stuffed human is not a generic figure (even assuming such a figure is feasible); it is Charlie Brown. Charlie Brown is a well-known and wellloved cartoon character in the comic strip, Peanuts. Assuming the study participants are familiar with this comic strip, it is unsurprising that the character of Charlie Brown is more likeable than the real human who looks very nice but whose character is not so immediately identifiable.

In Experiment 2, the likeability of the cartoon dog was found to be higher than both the stuffed dog (see Fig. 3, second line of images from the top; the cartoon dog appears far left and the stuffed dog appears far right) and the real dog (see the bottom row of images of dogs in Fig. 3; the real dog is at the far left). The cartoon dog is, of course, Snoopy, another well-known and well-loved character from Peanuts. Again, given its character form, this figure's likeability is predictable. Finally, the remarkable results of Experiment 3
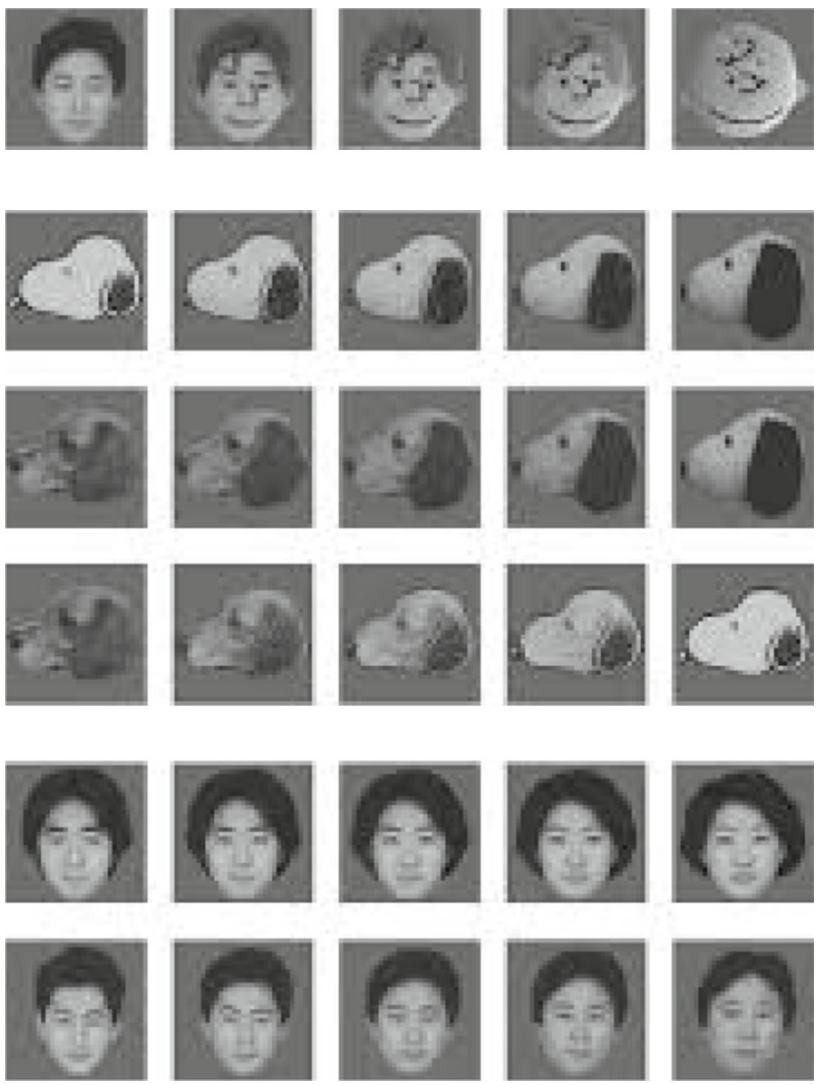

Fig. 3 The visual stimuli for Experiments 1, 2, and 3 for Yamada et al. [14]. (C) 2012 John Wiley and Sons. Reprinted, with permission, from Japanese Psychological Research

(see the bottom row of images of dogs in Fig. 3; the real dog is at the far left) are that the lowest likeability score corresponds with the real male face, which is at the far left of the series of morphed images, and the greatest likeability is scored by the face with the greatest category ambiguity (the middle face on the bottom row of images). This becomes less puzzling if you consider that the least likeable male figure on the bottom row (far left) is wearing a very serious expression and has slightly pointed eyebrows, a feature that casting directors would exploit; as already indicated, in a film, this figure might be cast as a villain.

Hanson et al.'s survey, meanwhile, 'show[s] a continuum of humanoid depictions, shifting from cartoonish to realistic over six frames' [7] (Fig. 4). The authors use the results of their survey to argue against the hypothesis that robots should not look or act in strongly humanlike ways. The problem with their study is that the humanlike model they use to disprove Mori's hypothesis is Princess Jasmine from Disney's Aladdin (1992).

The authors state that the results of their study "clearly showed that viewers found the whole continuum positively acceptable'. They continue: 'The reaction never dipped into the negative region, (and) thus showed no sign of the repul- 
sion that defined the "valley" of Mori's uncanny valley'. Though Hanson et al.'s discussions are persuasive elsewhere in their paper, their claims that participant responses to the images of Princess Jasmine disprove the veracity of Mori's hypothesis are less so. Princess Jasmine is another wellknown fictional character in the West, in this case, a heroine whose characteristics of beauty, high spirits, and a desire to marry for love make her likeable, whatever form she takes, be this animated or real. In fact, Princess Jasmine is at her most likeable, according to the study results, in the first two images where she is depicted as an animation. Despite the fact this contradicts Mori's hypothesis, this should be no surprise, given that this is Princess Jasmine's authentic form. The human version of her (see the far right of Fig. 4) is an 'artificial' representation, just as Snoopy's manifestation in Yamada et al.'s study as a stuffed animal is merely a version of his more likeable original cartoon form.

Having considered ways in which highly characterful figures influence studies testing for likeability, let us now consider the implications of an object devoid of character. Kriz et al.'s study [14] inquires into how people's attitudes to robots connect to their expectations about robots. Notably, the authors recognise the influential status of cultural depictions of robots in relation to people's expectations about them: their study results suggest, overall, that expectations about the 'robot's cognitive and social capabilities are highly correlated with how a wide variety of robots are depicted in fictional films'. However, certain capabilities, such as aggression, though common in fictional robots, scored low likelihood ratings in their survey, a finding that understandably surprised the authors.

This finding becomes less surprising when one considers the appearance of the PeopleBot used in their study (see Fig. 5). The robot looks a bit like a narrow treadmill frame, with two 'legs' positioned underneath a console comprising a tablet featuring the face of a white male, possibly in his late twenties or thirties, sporting a serious expression (although it is difficult to tell as the image is indistinct). Given that PeopleBot lacks arms, legs, or anything that might function as a weapon, it is unsurprising that respondents did not automatically conceive of the machine in aggressive terms. It would be a stretch to imagine the robot doing any damage to anything. In this sense, Kriz et al. are correct when they sur-

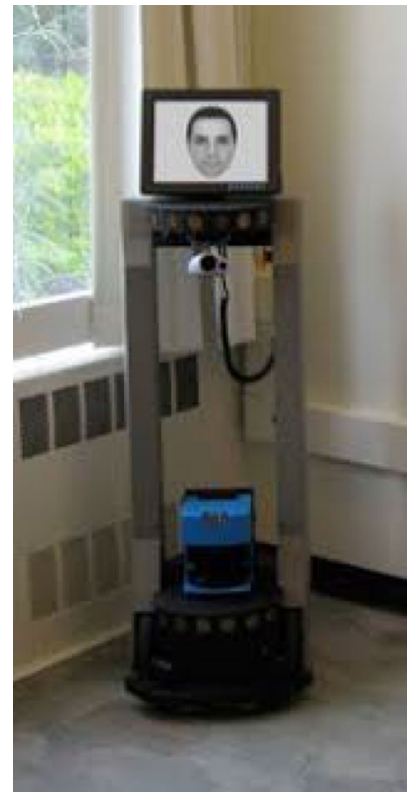

Fig. 5 The PeopleBot robot. (C 2010 IEEE. Reprinted, with permission, from IEEE Proceedings

mise that 'suspension of disbelief is finite'. Audiences need a sufficient and appropriate set of physical cues to inspire imaginative responses, which animate and anthropomorphise robots. PeopleBot, which is not at all humanlike, is hard to imagine possessing any kind of psychology or character. It is evidently a telepresence robot and, as such, its 'body' is a neutral platform for someone to 'bring to life' virtually.

\section{Some Reflections on the Uncanny}

In their study on the importance of predictive mechanisms in perceptions of artificial human forms, Urgen et al. suggest that 'incongruence between an object's appearance and motion' can give rise to uncanny responses [14]. The authors write that the 'uncanny valley could be explained by violation of one's predictions about human norms when encountered with realistic but artificial human forms'. This is to say, from an object's form, we infer how it will move (and, in the terms of this paper, how it will speak, act, and interact), and if
Fig. 4 These images relate to Hanson et al.'s test 2 [9]. () David Hanson
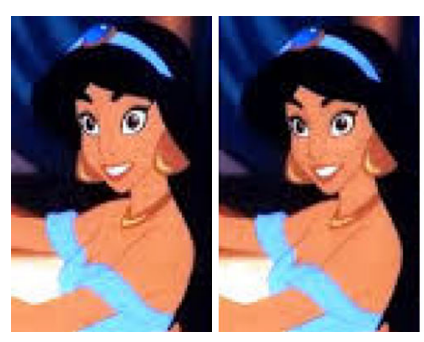
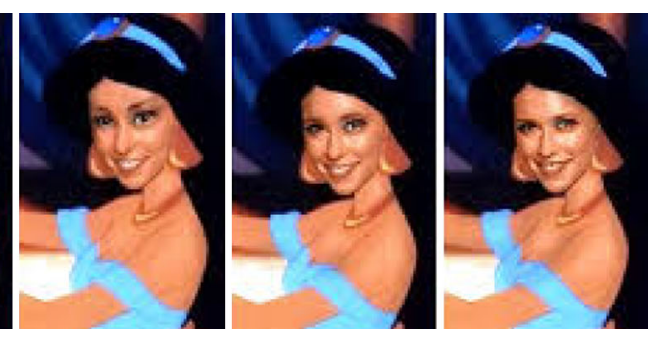
these expectations are violated, we experience an uncanny response.

Urgen et al. explain:

According to predictive coding, the uncanny valley is related to violation of expectations in neural computing when the brain encounters almost-but-not-quite-human agents. A growing body of work has associated Mori's hypothetical curve to the processing of conflicting perceptual or cognitive cues, in which the stimuli are compatible with the elicited expectations or are in violation of them. [14]

While the case is compelling - that our engagements with objects in the world are significantly cognitive, arising from experience and familiarity, and that incongruence between (character) expectations and behaviours may be bound up in uncanny responses-incongruence alone seems an insufficient cause for uncanniness. Incongruent character features, such as may arise between appearance, movements, and actions, can, for example, have comic effects. To evoke uncanniness, something more seems necessary, something pertaining to the form and quality of the incongruence, which, most likely, corresponds with a potential threat.

Certain objects seem to predispose audiences to uncanny responses through the ways in which they indicate particular types of narrative and audience engagement. Consider the figures of clowns and dolls as well as poltergeists and zombies, figures that explicitly indicate supernatural thrillers and horror films.

If, as this paper has already argued, humanlike artificial objects at the positive end of the shinwakan scale belong there because of their character forms and qualities, then objects appearing at the negative end must belong there because of their subverted character forms and qualities. If objects produce positive audience responses because they appear to be conscious, psychologically coherent characters that are friendly, familiar, and sociable (i.e. these objects appear to understand and like or love us), then objects at the negative end of the axis are likely to be psychologically incoherent, mysterious, irrational, or ambivalent, as well as strangely familiar; ${ }^{4}$ and their social status as 'friend' must be insecure (i.e. they appear not to understand or love or like us and, uncertain of their motivations, we sense that they may mean to do us harm).

Bruce Mangan, writing about the uncanny experience as fringe experience [14], observes that it seems 'to involve a rare and complex mix of familiarity, wrongness, and a feeling

\footnotetext{
${ }^{4}$ If Mori's terms - shinwakan and bukimi-are opposites, then familiar should appear as unfamiliar in its position at the negative end of the scale. However, given Freud's articulation of the uncanny and my analysis of uncanny objects, I find strangely familiar a more compelling negative articulation of familiar than unfamiliar.
}

of threat'. Anxieties may also arise, in a related way, from the discomfort of having to cognitively re-orientate ourselves in relation to a world that, while being semiotically familiar, appears phenomenally and simultaneously strange and unaccountable. Things are not as they seem. Consider Mori's discussion of the realistic prosthetic hand. He suggests that the experience of shaking such a hand, which, at first sight, looks real, produces an eerie sensation because of its 'limp boneless grip together with its texture and coldness' [14]. When we shake a realistic prosthetic hand, says Mori, 'we lose our sense of affinity, and the hand becomes uncanny'.

Mori's example of the prosthetic hand is revealing and resonates with an uncanny moment I experienced watching Geminoid F's performance in another one of Hirata's plays, Sayonara (2010) [14]. In this play, Geminoid F is cast in the role of companion to a young woman who is dying. There is a moment in the performance when the human actress takes the hand of the android and holds it to her cheek, implicitly expressing her desire to be physically comforted. (This is the moment shown in Fig. 2.) This particular action prompted a wave of distaste in me. Imaginatively identifying with the human character in the scene at an affective, embodied level, I intuited that the hand of the android would feel hard and lifeless or, to use Mori's terminology, 'limp' and 'boneless'. Also, it was evident that the robot did not return the young human woman's grip of its hand. This momentarily jolted me out of my anthropomorphic assumption that the robot is (human) like me. While maintaining imaginative engagement with this robot performer as a sophisticated android, I became abruptly and affectively aware that however humanlike this android appears, it remains ontologically and phenomenologically distinct: it is not flesh and blood, it will not die, and it does not feel. Its absence of living warmth seems suddenly distasteful, its hand evocative of that of a corpse; its relationship with time comes into view as something vastly different to human time, a difference that is strange and uncomfortable; and its incapacity to empathise with humans becomes abruptly and distastefully apparent.

Touch, whether real or imagined, may strongly stimulate responses to humanoid robots, perhaps because it moves us from reading the object semiotically to grasping it affectively. Rather than studying the object from a distance, we engage with it sensuously, and respond to it at a more involuntary level. Certainly, my own experience of meeting Pepper at the Science Museum for its 'Robots' exhibition ${ }^{5}$ indicates as much. The robot invited me to give it a fist bump. I had to perform the fist-bump with a degree of surprising robustness, then, pulling away, the robot wiggled its fingers at me. Without thought or hesitation, I copied it. This moment brought the interaction to life. For this moment, I stopped perceiving

\footnotetext{
${ }^{5}$ I visited the exhibition on 8 May 2017.
} 
the robot as something to study and marvel at and switched into an automatic mode of social engagement. The interaction moved from a performance to something that felt real. Knight may be correct in identifying 'full body gestures' as being important for tapping 'into our emotional experience in a uniquely human way' [14], but there is something about touch that may be particularly marked.

\section{Conclusion}

Drawing upon stage plays, theories of theatre and narrative studies, and robotics research, including Mori's theory of the uncanny valley, this paper has identified, explored, and interrogated elements important to the effective performance of likeable sociable humanoid robots. In particular, it has engaged with Mori's reference to total appearance and considered how it might be useful to robotics researchers. It has articulated ways in which Mori's notion of total appearance connects to realism in creating likeable sociable robots. And it has argued that theatre, including its elements of performance, aesthetics, character, and genre, can be employed to bring to light features of robotics research influential in the creation of humanlike objects that are likeable as opposed to uncanny.

This paper's key propositions and conclusions are that theatre can contribute much to the study and design of sociable robots, particularly in relation to understanding the importance of total appearance and character in the performance of likeable robots. Theatre also offers a lively and socially complex laboratory to explore compelling 'what if?' scenarios between human and robot characters.

The sociable robot is inherently a performer and needs to be engaged with as such. The humanoid robot is performative, i.e. it establishes its identity and role through the totality of its performance to a human audience or interacting person.

Theatre-makers, particularly Hirata and his play, Three Sisters: Android Version, show how character is a powerful element that can compensate for flaws in the physical performance of human likeness by robots. These performances, in combination with Mori's concept of shinwakan, indicate that kinship is almost certainly vital if artificial objects such as humanoid robots are to prompt positive (or negative) shinwakan in interacting humans.

This paper, drawing upon stage performances and robotics studies, has argued the importance of creating or representing aesthetically coherent representations of character, where all the parts of character coalesce to produce a socially identifiable figure whose behaviours are predictable. While uncanny responses to objects may arise because those objects appear both too humanlike but not humanlike enough, or else because of category uncertainty, this paper has attempted to show that details of character, including character incoher- ence, are also likely causes of degrees of likeability. Further, this paper has suggested that for a robot to be likeable, it may need to avoid pretending to be anything other than itself, a robot, however humanlike in appearance it may be. Acknowledgement of its distinct species form may be important.

This paper has argued that audiences observe stage figures and worlds with binocular vision. When they observe agents-human or otherwise-engaged in behaviours, they conjoin real and imagined elements to create a total impression of the performing object. Mori himself refers to such a tendency when he describes how audiences respond to the total appearance of bunraku puppets.

This paper suggests that binocular vision carries over into real life. Just as we read the subtext of characters performed by actors in a naturalistic play, so we read the clues available to us from the performances of people or sociable robots in the world and we infer and imagine the rest. Our engagement with a real object, be this object human or robot, is equally reliant upon a binocular and dialectical structure, which depends upon the active, imaginative participation of audiences. Real-life performance is different to staged performance not because it operates in the realm of empirical certainty as opposed to imaginative belief, but because it is really happening in the ongoing, improvised present and its stakes are real, not purely performative, as they generally are on the stage.

HRI research can exploit this capacity of humans to respond to performing objects both cognitively and affectively by attending more carefully to the total impression their artificial objects create through their physical appearance (including all features indicative of specific identity types and social/narrative roles), use of language, voice, gestures, types and qualities of actions, spatial positioning, quality and speed of speech and movement, as well as touch.

This paper, building on the work of Schwind et al. [14], argues that realism may be a broader and more subtle category than is suggested by degrees-of-realism of appearance. In the first place, in Mori's account of matters, the realism of some elements of appearance and context can offset or compensate for others that are less-than-realistic. In the second place, the concept of realism is complicated by the fact that it is sub-categorised and structured by genre. Observers attend to the total appearance of humanlike figures and, from these, they identify character type and role, i.e. what those characters do and how they relate to society. From such identification, the robot's behaviours become, crucially, predictable.

Furthermore, as Mori recognizes, total appearance trumps realism of humanlike appearance for the promotion of positive shinwakan, a position corroborated by this paper's analysis of Geminoid F's performance in Three Sisters: Android Version. Analysis of this play also indicates, by means of juxtaposing Geminoid $\mathrm{F}$ with her human coun- 
terpart, that species affinity is less important than character type and quality for the recognition of kinship. For positive shinwakan to be experienced, the interacting human needs to recognize in the object (or other human) a consciousness and character that bears some affinity with the human and appears to be friendly. A sociable and emotionally generous character seems much more likely to prompt feelings of kinship than an unsociable and emotionally close character, irrespective of species.

This paper argues that the uncanny is not an inherent quality of an artificial object. The uncanny is a quality of sensation arising from the interaction of a human with another human or object, with which it shares kinship of some kind but which appears to be ontologically other, or be operating at an inhuman level, such that it cannot be known or understood by the human. In the gap, the human imagination opens up to notions of the unknowable or, possibly, the supernatural.

As we come increasingly to share the human world with robots, and as sections of human society come to be cared for by them, the forms these robots take will be important to their effectiveness as social entities. If we are to enjoy friendly, trusting, and enjoyable relations with robots, they will need to be characterized in thoughtful ways, which correspond not only with the roles they are intended to play (as carers, shop assistants, instructors, medical assistants, and so on) but also with the identities of their intended interacting humans.

As Mori's own paper indicates, research in the field of HRI might really effectively draw upon theatre's artful placement and performance of humans, puppets, and objects in order to make relatively simple robots appear as likeable kin, capable of engendering real feelings of warmth and friendship in their interactions with humans. Just as fictional events on stage generate real absorption and real feelings of sadness or fear or happiness in audiences, so robots can be contextualized and constructed to appear, in the totality of their performances, as coherent and conscious characters, be their characters humanlike, animal-like, or something else. Properly cast, characterized, and scripted, robots - even relatively simple ones-can generate shinwakan in the humans with which they interact in social roles.

\section{Compliance with Ethical Standards}

Conflict of interest The author declares she has no conflict of interest.

Open Access This article is licensed under a Creative Commons Attribution 4.0 International License, which permits use, sharing, adaptation, distribution and reproduction in any medium or format, as long as you give appropriate credit to the original author(s) and the source, provide a link to the Creative Commons licence, and indicate if changes were made. The images or other third party material in this article are included in the article's Creative Commons licence, unless indicated otherwise in a credit line to the material. If material is not included in the article's Creative Commons licence and your intended use is not permitted by statutory regulation or exceeds the permitted use, you will need to obtain permission directly from the copyright holder. To view a copy of this licence, visit http://creativecomm ons.org/licenses/by/4.0/.

\section{References}

1. Birnbaum GE, Mizrahi M, Hoffman G, Reis HT, Finkel EJ, Sass O (2016) What robots can teach us about intimacy: the reassuring effects of robot responsiveness to human disclosure. Comput Hum Behav 63:416-423

2. Breazeal C (2003) Toward sociable robots. Robot Autono Syst 42:167-175

3. Bretan B, Hoffman G, Weinberg G (2015) Emotionally expressive dynamic physical behaviors in robots. Int J Hum Comput Stud 78:1-16

4. Čapek, K (1999 [1920/21]) R.U.R. (Rossum's universal robots) Majer P and Porter C (trans) Methuen Drama, London

5. Chemers M (2014) Phronesis for robots: (re)covering dramaturgy as an interdiscipline. In: Romanska M (ed) The Routledge companion to dramaturgy. Routledge, London, pp 364-369

6. Denisart C (2009) Robots. Dir. by Denisart C in a production by Les Voyages Extraordinaires. Film recording of performance: https://www.youtube.com/watch?v=bmfNbSYBjMA\&feature= youtu.be\&list=UUMbzJ3oSdOiivKt-08M28dQ . Accessed 27 Nov 2019

7. Hanson D, Olney A, Pereira IA, Zileka M (2005) Upending the Uncanny Valley. In: The twentieth national conference on artificial intelligence and the seventeenth innovative applications of AI conference, July 9-13, Pittsburgh, Pennsylvania, USA

8. Gray K, Wegner DM (2012) Feeling robots and human zombies: mind perception and the uncanny valley. Cognition 125:125-130

9. Harari YN (2011) Sapiens: a brief history of humankind. vintage Books, London, pp 114-128

10. Hirata O (2013) Q\&A with Hirata O, Ishiguro H, and Long B (DVD) Recorded in Feb 2013 while in New York touring I, Worker and Sayonara, both written and directed by Hirata O. Performed by Seinendan Theater Company + Osaka University Robot Theater Project

11. Hoffman G (2013) Robots with soul. Ted.com. TED, (online), Oct 2013. Accessed 28 Feb 2015

12. Hoffman G (2006) Acting lessons for artificial intelligence. In: 50th anniversary summit of artificial intelligence

13. Ishiguro H (2013) Q\&A with Hirata O, Ishiguro H, and Long B (DVD) February 2013

14. Jochum EA, Murphey T (2014) Programming play: puppets, robots, and engineering. In: Posner DN, Orenstein C, Bell J (eds) The routledge companion to puppetry and material performance. Routledge, London and New York, pp 308-321

15. Jochum E, Vlachos E, Christoffersen A, Grindsted Nielsen S, Hameed IA, Tan Z (2016) Using theatre to study interaction with care robots. Int J Soc Robot 8:467

16. Kawabe T, Sasaki K, Ihaya K, Yamada Y (2017) When categorization-based stranger avoidance explains the uncanny valley: a comment on MacDorman and Chattopadhyay (2016). Cognition 161:129-135

17. Knight H (2011) Eight lessons learned about non-verbal interactions through robot theater. Social robotics. Springer, Berlin, pp $42-51$

18. Knight H, Gray M (2012) Acting lesson with robot: emotional gestures. In: Video for the international conference on human-robot interaction, March, in Boston, MA, 407 
19. Knight H and Simmons R (2016) Laban head-motions convey robot state: a call for robot body language. In: International conference on robotics and automation

20. Kriz S, Ferro TD, Damera P, Porter III JR (2010) Fictional robots as a data source in HRI research: exploring the link between science fiction and interactional expectations. In: 19th IEEE international symposium on robot and human interactive communication, pp 458-463

21. LePage L (2016) 'Thinking something makes it so': Performing robots, the workings of mimesis and the importance of character. In: Adiseshiah S, LePage L (eds) Twenty-first century drama: what happens now. Palgrave Macmillan, Basingstoke, pp 279-302

22. LePage L (2016) Performance lecture: inside robot theatre: what happens when robots (and children) take to the stage? 20 April 2016, Bulmershe Theatre, Minghella Studios, University of Reading. https://www.robottheatre.co.uk/the-performance-lecture

23. LePage L (2018) Interacting nao. Video. https://www.youtube. $\mathrm{com} / \mathrm{watch}$ ? $=\mathrm{xN} 2 \mathrm{eJCL} 4 \mathrm{~N} 64$

24. Lin T-D (2015) Theater as a site for technology demonstration and knowledge production: theatrical robots in Japan and Taiwan. East Asian Sci Technol Soc Int J 9(2):187-211

25. Livermore M (2018) About a Bot. 22/11 productions (personal film recording of the performance, About a Bot, written and produced by Livermore $\mathrm{M}$ )

26. Lu DV, Smart WD (2011) Human-robot interactions as theatre. In: 20th IEEE international symposium on robot and human interactive communication, July 31-August 3, Atlanta, GA, USA, pp 473-478

27. Mangan B (2015) The uncanny valley as fringe experience. Interact Stud 16(2):193-199

28. Mori M (2012 [1970]) The Uncanny Valley. MacDorman KF \& Kageki N (trans). In: IEEE robotics \& automation magazine (online), pp 98-100. https://spectrum.ieee.org/automaton/robotics/ humanoids/the-uncanny-valley

29. Popat S (2015) Moving, withdrawing and the uncanny. In: Salazar NS, Popat S (eds) Digital movement: essays in motion technology and performance, Palgrave studies in performance technology. Palgrave, Basingstoke, pp 131-147

30. Poulton C (2014) From puppet to robot: technology and the human in Japanese theatre. In: Posner DN, Orenstein C, Bell J (eds) The Routledge companion to puppetry and material performance. Routledge, London and New York, pp 280-293
31. Sayonara (2010) Tokyo: Seinendan Theater Company + Osaka University Robot Theater Project. Written and directed by Hirata O (DVD)

32. Schwind V, Leicht K, Jäger S, Wolf K, Henze N (2018) Is there an uncanny valley of virtual animals? A quantitative and qualitative investigation. Int J Hum Comput Stud 111:49-61

33. Soloski A (2012) Performance review: Seinendan Theater Company + Osaka University Robot theater project. Written and directed by Hirata O. Japan Society, New York City, 7 February 2012. Theatre J 65(3):400-402

34. Spillikin: A Love Story (2015) Pipeline Theatre Company (personal film recording of the performance, Spillikin, written and directed by Welch $\mathrm{J}$ )

35. States BO (1992) Great reckonings in little rooms: on the phenomenology of theater. University of California Press, California

36. Talenti F (2013) The Uncanny Valley. Written and dir. by Talenti F, starring a RoboThespian ${ }^{\mathrm{TM}}$ (by engineered arts). First performed at Swain Hall, UNC, then at Brick Theater, New York

37. Three Sisters: Android Version (2012) Tokyo: Seinendan Theater Company + Osaka University Robot Theater Project. Written and directed by Hirata O (DVD)

38. Uncanny Valley (2019) Rimini Protokoll and Thomas Melle (available to view at https://www.rimini-protokoll.de/website/en/videos)

39. Urgen BA, Kutas M, Faygin AP (2018) Uncanny valley as a window into predictive processing in the social brain. Neuropsychologia 114:181-185

40. Wang S, Lilienfeld SO, Rochat P (2015) The Uncanny Valley: existence and explanations. Rev General Psychol 19(4):393-407

41. Yamada Y, Kawabe T, Ihaya K (2013) Categorization difficulty is associated with negative evaluation in the "uncanny valley" fphenomenon. Jpn Psychol Res 55(1):20-32

Publisher's Note Springer Nature remains neutral with regard to jurisdictional claims in published maps and institutional affiliations. 